\title{
THE EFFECTIVENESS OF TED TALKS TOWARDS STUDENTS' PROFICIENCY LEVEL
}

\author{
Azureen Abd Aziz ${ }^{1}$ \\ Centre of Liberal Arts and Languages (COLAL), \\ Inti International University, Malaysia \\ (Email: azureen.abdaziz@ newinti.edu.my) \\ Suhaila Ngadiron ${ }^{2}$ \\ Centre of Liberal Arts and Languages (COLAL), \\ Inti International University, Malaysia \\ (Email: suhaila.ngadiron@newinti.edu.my)
}

Accepted date: $20-04-2019$

Published date: 08-07-2019

To cite this document: Aziz, A. A., \& Ngadiron, S. (2019). The Effectiveness of TED Talks towards Students' Proficiency Level. International Journal of Education, Phycology, and Counselling, 4(31), 296-304.

DOI: $10.35631 / \mathrm{IJEPC} .4310026$

Abstract: Proficiency has become a crucial aspect of learning English language. The aim of this study is to find out the effectiveness of using English videos from TED talks towards students' proficiency level. This study employed a quantitative research design. To fulfil this purpose, 50 diploma students were selected from a private university in Negeri Sembilan. These participants were then divided into two equal groups of experimental and control. A graded presentation was administered as a pre-test for both groups prior to the treatment. There were three sessions of presentations conducted with both groups in which the experimental group watched the TED talks and the control group underwent the traditional teaching method. After the sessions, post-test were given to both groups. The scores of both tests were collected and analyzed using descriptive statistics. Results revealed that the experimental group experienced improvement in their speaking compared to the control group. Few recommendations are presented based on the research findings.

Keywords: Proficiency. TED Talks, Videos, University

\section{Introduction}

Students face problems in delivering speech confidently in front of a crowd. They only remember at the time when they do their memorizing, and later they forget again. Hence, students are not motivated to speak nor present in English language during their tertiary level of studies. Because of the problem, students might consider that speaking and presenting in front of a group of people is difficult and they are also not interested anymore in mastering it as their teacher rarely create instructional media. This shows that a creative way of learning is needed to master these aspects. This study is important as most of the students in the selected university are still unable to speak confidently. However, the focus of the study is to investigate the effectiveness of TED Talks towards students' proficiency level. Hence, this study will focus 
on the effectiveness of using TED talks towards students' language proficiency. Notwithstanding this, this study will provide useful information to teachers and students. Teachers can take this chance to start their class with this strategy and evaluate it whether it is better to be applied in the classroom and students will have better improvement on their proficiency level

\section{Literature Review}

\section{Social Media}

Social media plays an important role in the daily lives of most people including language learners and can also be used to support language development. Righini (2014) describes how social media can be used to develop skills needed to read authentic texts and news articles from the electronic media. News articles on topics of interest were taken from BBC News, CNN World, The Guardian, The New York Times, The Australian, and assigned at the end of each lesson as self-study. Students were asked to choose one a week and teachers were encouraged to create a blog where students would upload comments on their chosen news article and comment on their peers' posts. In order to encourage student participation teachers employed different forms of interacting with students on the blogs and also with different social media tools, such as voice recording capable websites (voicethread or voxopop, for example) and micro blogging, mainly Facebook. Mahoney (2014) in London describes how he uses blogging in a writing course, making use of Creative nonfiction (CNF) - the use of creative literary techniques and devices when writing about non-fiction events, e.g. diaries, memoirs, autobiographies, essays, obituaries, journalism and travel writing.

\section{A Video Documentary}

Miller and Hafner in Hong Kong describe how students in an ESP course collaborate out-ofclass to produce a video (Miller and Haffner, 2014: 212). In this project university students invest their time beyond the classroom when asked to create a digital video project, which documents a simple scientific investigation. This digital video project is part of a credit-bearing EAP course all science students have to take in order to complete their programme in an English medium university in Hong Kong. The project is structured as an integral part of the course and students work in groups outside of class time to create their own scientific documentary which they then up-load onto YouTube. During the course, the students are introduced to the concept of how scientific texts can be presented using different genres: the scientific documentary vs the lab report. They are also introduced to some simple technology which they can use when making a digital video. Then, the students are given freedom to decide on the type of documentary (observational, expository, and participatory); write their own script; prepare a storyboard; record the video footage; and present their scientific findings in as creative a fashion as they like. The results show that when given responsibility for creating a scientific documentary these students invest a large amount of their own time out of class and develop a number of skills: cooperative learning, learner autonomy, and language skills. They invest their time for a number of reasons: They are aware of a potentially large authentic internet audience who may view their work; they want to present their oral skills well on video; they enjoy the process of being creative and want to showcase their work to the best of their ability.

\section{Internet Television}

Lin and Siyanova-Chanturia (2014) point out many young people like to watch TV dramas, soap operas and comedies as a source of input of authentic, everyday English but that until recently, accessing them has been problematic in many situations. However with the advent of 
internet television (television delivered on any internet-enabled devices such as smartphones, tablets, personal computers using video streaming), the learner can take internet television with them wherever they go, accessing their favorite programme with just a few clicks on the internet-enabled smartphone. With internet television readily available, learners are no longer limited to watching movies in a selfaccess centre and can spend 'dead time' on the subway, bus, or bus stop, watching television programmes in English.

\section{Speech Through Videos}

Using videos in a classroom is a creative way and special thing that happens rarely. Videos provide the materials in English that students are able to understand clearly. They are also able to enjoy the videos and recognize the wordings. It becomes the educator's responsibility to provide a different way in learning English as they could use Ted Talks and provide an appropriate video which is suitable. According to Griffe (1992), there are four categories which are:

1. The class, including the total number of students and their age, the time of the day, the language level of the students and their interest.

2. The teacher, including their age and interest as well, classroom support to convey videos and teacher's purpose.

3. Classroom Opportunities, including teachers' level of independence in determining the material of curriculum, free class time and lesson supplement.

4. The music, including the kind of video interest, the song that requires support to the lesson and lesson plan.

Educators should decide based on the criteria as above of an appropriate video, and find a video in Ted Talks. There are many ways to introduce the videos and to improve vocabulary in the classroom. One of the ways that an educator can use in their classroom is by using vocabulary video. First, play the video with no hands outs. Then, educators instruct students to listen to the video and give them the words in a minute. Subtitles will then be shown to the students and they are required to present their understanding about the video. Next, educators play the video again and students must listen and come out with the words and phrases that they do not understand. Lastly, they discuss the circled solve the vocabulary matter together.

There are many other ways to teach vocabulary in a classroom by using videos as the materials. Educators in this case need to be well prepared to teach the students using videos. Pay attention about the selected class, the students and teachers in order to choose an appropriate video. Then, decide the suitable ways in conveying the video to the students. Related past studies at the end of its first five years of service, Ted Talks was receiving more than 2 billion views per day and users were watching more than 35 hours of video per minute (Walk, 2010). Although Ted Talks was created as a video-sharing service for the everyday user, the potential for educational use has not gone unnoticed. These videos comprise only a portion of the content on YouTube with potential educational value. The growth of educational video on Ted Talks runs concurrent with broader trends in educational video viewership, which rose from $22 \%$ to 38\% between 2007 and 2009 (Purcell, 2010). The findings showed that the videos are used for two purposes: class presentations and icebreaking. Lecturers prepared a video or audio based on textbook and plays it for a few times. Both lecturers and students watch the video together and this makes the students familiar with the presentation styles, body language, and the voice modulation in the video. The lecturer guides them to learn and apply the techniques that they had watched from the video. Based on the results, the lecturers gave the students a topic for them to present, and asked the students to present the topic using the techniques that they had watched in Ted Talks. The problem faced by the lecturer to measure the students' proficiency 
level using Ted Talks is the students do not know the meaning and do not know how to pitch the words in the videos.

\section{Related Past Studies}

Consequently, a study conducted by ChunxuanChen (2009) investigated about using English videos as an enjoyable and effective approach to English Language Teaching (ELT). This study explained about the application of videos in ELT. The results showed that by using English videos would not weaken the teaching process but it reinforces the effect of teaching. This study also provides practical supports and arguments for using English video in ELT. The potential of Ted Talks for online education has been examined previously (Snelson, 2014). One of the obvious benefits of using Ted Talks in online education is that it provides online access to vast quantities of free public video on a broad spectrum of topics. It is a simple matter to link to or embed Ted Talks videos in online course content or discussion forums. Content management is also a benefit. Online educators can establish Ted Talks to collect, organize, host, and distribute video.

Lastly, concurrent with the growing educational interest in Ted Talks is the emergence of Ted Talks appearing in peer-reviewed journals and conference proceedings. Topics discussed in the literature include, but are not limited to, uncovering the experiences of Ted Talks users (Lange, 2007), and possibilities for teaching with Ted Talks (Burke \& Snyder, 2008; Snelson, 2009; Tamim, Shaikh, \& Bethel, 2007).

\section{Methodology}

The study took the form of quasi-experiment adopting the quantitative method. There were an experimental group and a control group. Having two different class of students aim to know the effectiveness of the students proficiency via Ted Talks. The study took place in a Private university located in Negeri Sembilan from September 1st until 4th 2018. A total of 50 diploma students were selected as the participants in this study. The researcher determined the participants by using purposive sampling. The sample is taken on the basis of their judgement of their typicality of the particular characteristics being sought (Cohen et.al, 2007).

In this case, the researcher chooses the class and participants based on lecturer's judgement. Therefore, the researcher took two classes namely 1A2 (25 students) as the control class and 1A3 (25 students) as the experimental class according to their English lecturer's view in university. In order to avoid any misinterpretation of invalidity, the researcher decided to use two heterogeneous groups. The only difference between the two groups was that one group the (experimental group) was exposed to the treatment of using videos in Ted Talks while the other group (control group) experienced the traditional teacher-fronted method. Pre-test and post-test were used as the research instruments in this study to collect data. Pre-test were given to both groups of students before the treatment.

Then, students in the experimental groups used English videos from Ted Talks and the control group without using English videos from Ted Talks. After three sessions, both groups were given post-test. The test was used in order to know the effectiveness of students' proficiency via videos from Ted Talks towards the diploma students' in a private university located in Negeri Sembilan. Test technique is the only technique in collecting the data. A proficiency test, served as a pre-test, was given to participants in both classes (1A2 and 1A3). This test was carried out to get their score and to know students ability about their proficiency level.

On the next day, the treatment of the study was carried out to the experimental group. They received the proficiency lessons with the treatment of using videos in Ted Talks. The control 
group, on the other hand, did not receive any treatment process. Instead, this group was taught using the traditional teacher-fronted method without the use of videos throughout the period. Both groups were observed by the researcher. After a day, both groups were given a proficiency test which served as the post-test in the form of multiple choices.

This test was conducted to know the improvement of students' ability in their proficiency level after undergoing the treatment. Data collected from the pre-test and post-test was calculated in the form of scores. The scores were then processed using descriptive statistics, according to frequency and mean. The differences of the two tests were recorded to observe whether there are significant differences between students' achievements before and after the treatment using Ted Talks videos.

\section{Findings and Discussions}

The tests were done in two classes, those were in $1 \mathrm{~A} 2$ as the controlled group and those who were in A13 class were the experimental group. The researcher obtained data from the objective test which was in the form of multiple choices questions. Both test consisted of 20 items. The accumulation of the correct item was multiplied by 5 by the researcher. This was done so that it would be accumulated to $100 \%$ of the test marks.

\begin{tabular}{|c|c|c|c|}
\hline $\begin{array}{l}\text { Number of } \\
\text { Participants } \\
\text { N) }\end{array}$ & \multicolumn{2}{|c|}{$\begin{array}{c}\text { Controlled } \\
\text { Class (1A2) }\end{array}$} & $\begin{array}{c}\text { Gained } \\
\text { score }\end{array}$ \\
\cline { 2 - 4 } & $\begin{array}{c}\text { Pre- } \\
\text { Test }\end{array}$ & $\begin{array}{c}\text { Post- } \\
\text { Test }\end{array}$ & \\
\hline 1 & 50 & 60 & 5 \\
\hline 2 & 60 & 60 & 0 \\
\hline 3 & 35 & 40 & 5 \\
\hline 4 & 60 & 65 & 5 \\
\hline 5 & 40 & 50 & 10 \\
\hline 6 & 60 & 65 & 5 \\
\hline 7 & 70 & 70 & 0 \\
\hline 8 & 60 & 70 & 10 \\
\hline 9 & 70 & 70 & 0 \\
\hline 10 & 70 & 75 & 5 \\
\hline 11 & 50 & 55 & 5 \\
\hline 12 & 65 & 75 & 10 \\
\hline 13 & 60 & 75 & 15 \\
\hline 14 & 50 & 55 & 5 \\
\hline
\end{tabular}




\begin{tabular}{|c|c|c|c|}
\hline 15 & 60 & 65 & 5 \\
\hline 16 & 45 & 55 & 10 \\
\hline 17 & 70 & 70 & 0 \\
\hline 18 & 65 & 70 & 5 \\
\hline 19 & 45 & 45 & 0 \\
\hline 20 & 65 & 75 & 10 \\
\hline 21 & 75 & 75 & 0 \\
\hline 22 & 50 & 60 & 10 \\
\hline 23 & 60 & 70 & 10 \\
\hline 24 & 65 & 70 & 5 \\
\hline 25 & 60 & 65 & 5 \\
\hline$\sum \mathbf{N}=\mathbf{3 0}$ & $\sum=$ & $\sum=$ & $\sum=\mathbf{X}_{\mathbf{2}=140}$ \\
& $\mathbf{X}_{\mathbf{1}=1535}$ & $\mathbf{X}_{\mathbf{1}}=1535$ & \\
\hline Mean & $\mathbf{5 8 . 4}$ & $\mathbf{6 1 . 4}$ & $\mathbf{5 . 6}$ \\
\hline Max & $\mathbf{7 5}$ & $\mathbf{7 5}$ & \\
\hline Min & $\mathbf{3 5}$ & $\mathbf{4 0}$ & \\
\hline & & & \\
\hline
\end{tabular}

Table 1: Students Score of Pre-test and Post-test of the Controlled Group (1A2)

Based on the above table (Table 1), the score of pre-test and post-test of the controlled class (1A2) showed that the highest score on the pre-test was 75 and the lowest score obtained was 35 with the mean of 58.4. Besides, the highest score obtained during the post-test was also 75 while the lowest score was 40. The mean of the post-test was 61.4. It can be seen that the controlled class only gained score about 5.6

\begin{tabular}{|c|c|c|c|}
\hline $\begin{array}{l}\text { Number of } \\
\text { Participants } \\
(\text { N) }\end{array}$ & \multicolumn{2}{|c|}{$\begin{array}{c}\text { Controlled } \\
\text { Class (1A2) }\end{array}$} & $\begin{array}{c}\text { Gained } \\
\text { score }\end{array}$ \\
\cline { 2 - 4 } & $\begin{array}{c}|c| \\
\text { Pre- } \\
\text { Test }\end{array}$ & $\begin{array}{c}\text { Post- } \\
\text { Test }\end{array}$ & \\
\hline 1 & 80 & 95 & 15 \\
\hline 2 & 45 & 65 & 20 \\
\hline 3 & 75 & 95 & 20 \\
\hline 4 & 55 & 65 & 10 \\
\hline 5 & 50 & 90 & 15 \\
\hline & & & \\
\hline
\end{tabular}




\begin{tabular}{|c|c|c|c|}
\hline 6 & 60 & 75 & 25 \\
\hline 7 & 65 & 85 & 25 \\
\hline 8 & 65 & 75 & 10 \\
\hline 9 & 70 & 80 & 10 \\
\hline 10 & 70 & 85 & 15 \\
\hline 11 & 60 & 75 & 15 \\
\hline 12 & 45 & 65 & 20 \\
\hline 13 & 70 & 90 & 25 \\
\hline 14 & 60 & 85 & 25 \\
\hline 15 & 55 & 85 & 25 \\
\hline 16 & 80 & 90 & 10 \\
\hline 17 & 50 & 70 & 20 \\
\hline 18 & 65 & 90 & 25 \\
\hline 19 & 60 & 75 & 15 \\
\hline 20 & 75 & 85 & 10 \\
\hline 21 & 75 & 95 & 20 \\
\hline 22 & 70 & 80 & 10 \\
\hline 23 & 75 & 90 & 15 \\
\hline 24 & 70 & 85 & 15 \\
\hline 25 & 65 & 85 & 20 \\
\hline$\sum \mathbf{N}=\mathbf{3 0}$ & $\begin{array}{c}\sum= \\
X_{1=1620}\end{array}$ & $\begin{array}{c}\sum= \\
X_{1=2050}\end{array}$ & $\sum=\mathbf{X}_{2=430}$ \\
\hline Mean & 64.8 & 82.0 & 17.2 \\
\hline Max & 80 & 95 & \\
\hline Min & 45 & 65 & \\
\hline
\end{tabular}

Table 2: Students Score of the Pre-Test and Post-test of the Experimental Group (1A3)

As can be seen on the table above (Table 2), as for the pre-test, the highest score obtained was 80 and the lowest score was 45 with the mean of 64.8. Consequently, the highest score as for the post test was 95 and the lowest score was 65 . It can be seen that the experimental group showed great rise up in terms of their scores. Meanwhile, the mean of pre-test which was (64.8) increased on the post-test up to 82.0. It can also be seen that the experimental group (1A3) gained 17.2 in terms of points. 
Based on the analysis of the above data, there was a significant difference between students achievement on vocabulary competency in experimental group (1A3) which used Ted Talks as their medium to find appropriate English videos. Meanwhile, the controlled group (1A2), did not used Ted Talks to learn vocabulary. It can be seen from the students' pre-test and post-test score.

The pre-test mean score of the students in experimental group was 82.0, and the mean of posttest of students in experimental group was 64.8. On the other hand, the pre-test score in controlled group (1A2) was 58.4, and the mean score of the post-test was 61.4. Findings from this study closely mirror previous study results. Like Jauhara (2009) and Alimemaj (2010) noted that the participants' perception of using Ted Talks was positive. However, that students' perceptions were studied in their study without exploring the effectiveness of using Ted Talks videos towards students' proficiency level. This study fill that gap.

\section{Conclusion and Implications}

In improving students' competency level, it is important to choose appropriate technique. The application of Ted Talks videos is considered as one of the effective ways to measure the proficiency as it created enjoyment in learning process and make students attracted to learn the English Language. The students are the one who learn the language so they should be the centre of teaching and learning process. By using Ted Talks as a medium in measuring the students' proficiency level, students become active learners who experienced what they are learning. As a matter of fact, the findings have shed light that the experimental group had far more significant improvement in their proficiency competence as compared to the control group.

In view of the limitations, there is a need for further research to be conducted with a bigger sample size which will help to obtain more data and confirm the findings. Plus, a longer experimental period is needed to enable the researcher to draw valid conclusions to see whether the improvements are consistent. This study provides useful information to teachers, students and other researchers. Teachers can start trying out this method to teach their students and students can improve their proficiency level. Other researchers can use this study as their references to conduct similar studies. Hence, it can be concluded that English songs from YouTube are effective towards students' vocabulary competency. This proved that students' proficiency level after using English videos in Ted Talks were better and shows improvement in terms on achievement compared before they were given the treatment. In addition, teaching English using Ted Talks can help students to remember vocabulary easily, because they were stimulated by videos.

\section{References}

Adhele LelyanaKisworoPutri. (2015). The Use of Song Lyrics for Teaching Vocabulary at SMP,Amal MulyaTawangMangu. School of Teaching Training and Education Muhammadiyah University of Surakarta.

Alimemaj, Z. (2010). YouTube, Language learning and Teaching Techniques. Retrieved from http://www.anglohigher.com/magazines/magazine-detail/61/32.

Barska, K. (2006). Using songs to teach vocabulary to EFL students. Retrieved from http://www.ac-grenboble.fr/reaso/article.php3?id_article=58

Beare,K.(2010).Music Music in the ESL classroom Retrieved from http://esl.about.com/od/esleflteachingtechnique/a/brainmusic.html

Brewster, J., Elis, G., Girrard, D. (2003). The Primary English Teacher's Guide. Essex: Pearson Education Ltd. Calderon, M., August, D., Slavin, R., Duran, D., Madden, N., 
Cameron, L. (2003). Teaching Languages to Young Learners. Cambridge: Cambridge University Press.

Chuxuansheng. (2009). Using English Song: An Enjoyable and Effective Approach to ELT. English Language Teaching. Volume 2, No. 1, MacMillan University

Cohen. L, Manion.L\&Morrison.K. (2007). Research Method in Education. Sixth Edition, New York: Madison Avenue, p.114.

Dowse, C. (2009). Teaching: How to use YouTube to teach. Retrieved from http://cd2006.blogspot.com/2009/05/teaching-how-to-use-youtube-to-teach.html

Griffee, Dale T. (1992). Songs in action. Trowbridge: Prentice Hall International

Harmer, J. (2007). The Practice of English Language Teaching (4th Ed). United Kingdom: Pearson Education Limited.

Hatch, E \&Lazaration, A. (1991). The Research Manual: Design and Statistic for Applied Linguistic. Massachusetts: Heinle publisher.

In Kamil, M.L \& Hiebert E.F. (2005). (Editor). Teaching and Learning Vocabulary: Bringing Research to Practice. New Jersey: Lawrence Erlbaum Associates.

Jauhara, D. (2009). Teaching Vocabulary to Young Learners by Using Youtube. Conaplin2 (August 3 rd - 4 th, 2009). Bandung: Balai Bahasa Universitas Pendidikan Indonesia.

John Wrenshall. (2002). Using songs to Improve Communication Competence. Bangkok: November. AUA Language Center.

Kelsey, T. (2010.) Social networking spaces. New York: Apress. Retrieved from http://dx.doi.org/10.1007/978-1-4302-2597-3

Lotfi Ghazal. (2002). Learning Vocabulary in EFL Context through Vocabulary Learning Strategies. Novitas Royal. Vol. 1, no.2, p. 84.

Nation, I. S. P. (2001) Learning vocabulary in another language. Cambridge: Cambridge University Press.

Ottilie. (2010). Is English compulsory course in your country? Retrieved from http://forum.wordreference.com/showthread.php?t=1196978\&page =3

ShaheenAra. (2009). Use Songs, Rhymes, and Games in Teaching English to Young Learners in Bangladesh. The Dhaka University Journal of Linguistics, Volume 2, no. 3. Pp. 161-172.

Xmarabout. (2010). Is English compulsory course in your country? Retrieved from http://forum.wordreference.com/showthread.php?t=1196978\&page=3 